\title{
Marketing Lightly Processed Fruits and Vegetables
}

\author{
Donald V. Schlimme \\ Department of Horticulture and Landscape Architecture, Holzapfel Hall, University of Maryland, College Park, \\ MD 20742-5611
}

\section{INTRODUCTION}

The term "marketing" has been defined by Best (1991) to encompass the entire process by which new product opportunities are identified, designed, manufactured, and promoted to provide products that meet consumer needs. Successful marketing of lightly processed (LP) fresh produce in the United States is, in large measure, inexorably linked to several factors, the most important of which is maintenance of a high level of sensory quality for an adequate duration subsequent to harvest (Gertmenian, 1992). Other factors that are of vital import to successful marketing of LP produce include harvest timing to achieve peak quality; quality controls for postharvest treatments; effective packaging using informative graphics, including branding; competitive pricing; and providing service at all levels of the distribution system (Allen and Pierson, 1988).

In the early 1970s, a greater concern with nutrition, health, and physical fitness began to exert an influence on food marketing and food consumption in the United States. By 1987, 11.3 billion $\mathrm{kg}$ of fresh fruit, 10.0 billion $\mathrm{kg}$ of commercially produced fresh vegetables, and 5.2 billion $\mathrm{kg}$ of fresh potatoes (Solanum tuberosum L.) were used in the United States (How, 1990). Sales of fruit in fresh form have risen from $\approx 34 \mathrm{~kg}$ per person in the early 1970 s to almost 45 in 1990 . Per capita use of the 10 commercially produced fresh vegetables currently reported increased from $\approx 32 \mathrm{~kg}$ in the early $1970 \mathrm{~s} \mathrm{to} \approx 44 \mathrm{~kg}$ in the mid to late 1980s (How, 1990). Demand for fruits and vegetables is illustrated by increased per-capita fresh fruit and vegetable consumption. United States per capita fresh fruit and vegetable consumption in 1988 was $15 \%$ and $26 \%$ greater, respectively, than in 1978. Simultaneously, there has been a general shift in consumption toward "likefresh" quality and away from consumption of canned vegetables (Cook, 1992). Marked changes in produce sales occurred during the 1980 s, as demonstrated by an increase from $19 \%$ to between $38 \%$ and $45 \%$ in total fresh produce shipments marketed through food service establishments (Cook, 1992). The amount of fresh fruits and vegetables in U.S. markets between 1980 and 1988 increased by $30 \%$ or 7.4 billion $\mathrm{kg}$. During this time, imports of fresh produce increased by $55.5 \%$ (Cook, 1992).

In 1988, total shipments of fresh fruits and vegetables for domestic and export markets from the United States was 26.0 billion $\mathrm{kg}$. The major sources, by state, of these total shipments were California (39.3\%), Florida (14.2\%), Washington (7.4\%), Idaho (5.7\%), Arizona (4.5\%), and Texas (4.5\%), all distant from major markets in the central and eastern United States (How, 1990). The average percentage of the 10.5 billion $\mathrm{kg}$ of the seven leading fresh fruit and vegetable commodities arriving at 23 U.S. cities in 1986-88 were potatoes $(14.5 \%)$, bananas (Musa $\times$ paradisiaca L.) (9.4\%), crisphead lettuce (Lactuca sativa var. capitata L.) (8.6\%), tomatoes (Lycopersicon esculentum Mill.) (5.3\%), onions (Allium cepa L.) (5.2\%), oranges (Citrus sinensis) (5.2\%), and apples (Malus sylvestris Mill.) (5.1\%) (How, 1990).

According to How (1990), the single most important change that affected the entire produce industry occurred in the early 1970s with the reversal of the trend by consumers toward processed fruits and vegetables in favor of fresh. The key to successful marketing of fresh produce in the future will be to provide a constant supply of uniformly high-quality products.

\section{CHARACTERISTICS OF LIGHTLY PROCESSED FRUITS AND VEGETABLES}

All LP fruits and vegetables are perishable and demonstrate rapid postharvest quality degradation over time under ambient storage. LP fresh produce is more perishable than unprocessed fresh produce (Cantwell, 1992) as a consequence of tissue damage resulting from processing operations such as cutting, slicing, shredding, peeling, trimming, coring, and the like. LP fruits and vegetables are, of course, living plant tissues that usually receive washing, sanitation/preservation treatment, or both before being packaged for refrigerated distribution and marketing. Many synonyms are used for the term "lightly processed," including minimally processed (MP), partially processed, and fresh processed. LP produce is also referred to as precut, preprepared, cut prepared, convenience, fresh-cut, and value-added produce (Cantwell, 1992).

Many forms of LP produce are prepared, packaged, and marketed in the United States (Table 1), but the table does not list nearly all of the items available.

Numerous pre- and postprocessing factors influence retention of high quality or marketable "shelf life" of LP vegetables. Gertmenian (1992) estimates the average refrigerated (0.6 to 3.3C) shelf lives of LP vegetables to be as short as 5 days [for jicama (Pachyrhizus erosus $\mathrm{L}$. Urban) sticks and sliced mushrooms (Agaricus sp.)] to as long as 18 days (for cleaned and cored crisphead lettuce). Whole or unprocessed fresh fruit and vegetable shelf life at -1 to $4 \mathrm{C}$ ranges from 1 to 5 days for strawberry (Fragaria chiloensis L. Duchesne $\times F$. virginiana Duchesne) to 8 to 30 weeks for apples and pears (Pyrus communis L.) (Wills et al., 1989).

\section{TOOLS USED FOR MARKETING LP FRUITS AND VEGETABLES}

\section{Temperature control}

Because a high level of sensory quality is a requisite for successfully marketing LP fruits and vegetables, maintaining the product at the proper temperature immediately after harvest, throughout distribution, and up to consumption is the most important marketing goal; Gertmenian (1992) identified temperature maintenance as the primary marketing tool.

Table 1 . Commonly marketed LP fruits and vegetables.

\begin{tabular}{|c|c|}
\hline Commodity & LP forms \\
\hline \multicolumn{2}{|l|}{ Fruit } \\
\hline Apples & Peeled and cored, cored and sliced \\
\hline Oranges & Peeled sections and slices, wedges \\
\hline Kiwi (Actinidia chinensis L.) & Peeled and sliced \\
\hline \multicolumn{2}{|c|}{ Pineapple } \\
\hline (Ananas comosus L. Merr.) & $\begin{array}{l}\text { Peeled and unpeeled slices, chunks, cored } \\
\text { peeled cylinders }\end{array}$ \\
\hline Strawberries & Washed, destemmed, sliced \\
\hline Melons (Cucumis melo L.) & Balls, chunks, slices with and without rind \\
\hline \multicolumn{2}{|l|}{ Grapefruit } \\
\hline (Citrus paradisi Macfad.) & Peeled and sections \\
\hline Grapes (Vitis vinifera L.) & Washed and destemmed \\
\hline Mixed & Wide variety of precut fruit \\
\hline \multicolumn{2}{|l|}{ Vegetable } \\
\hline Beets (Beta vulgaris L.) & Peeled, shredded, cut, sliced, julienne \\
\hline \multicolumn{2}{|l|}{ Broccoli } \\
\hline (Brassica olerac & Individual florets with or without stalk \\
\hline Carrot (Daucus carota L.) & Peeled slices and sticks, diced, shredded \\
\hline Celery (Apium graveolens L.) & Trimmed sticks, diced, sliced stalks \\
\hline \multicolumn{2}{|l|}{ Cucumber } \\
\hline (Cucumis sativus L.) & Sliced, crinkle cut, wedges \\
\hline Lettuce & Cleaned and cored, cored and chopped \\
\hline Onions & Sliced, rings, diced \\
\hline \multicolumn{2}{|l|}{ Spinach } \\
\hline (Spinacia oleracea L.) & Cleaned, trimmed individual leaves \\
\hline Tomatoes & Sliced, diced, wedges \\
\hline Mixed vegetable salads & Wide variety of precut vegetables \\
\hline
\end{tabular}


Quality degradation is retarded by decreasing the temperature of plant tissue (to a point just above the freezing point of nonchillingsensitive tissues or just above the point at which chilling injury occurs for sensitive produce). $Q_{10}$ values for many fruit and vegetable biological processes are highest (up to 7) between 1 and 10C and are usually between 2 and 3 above 10C (Wills et al., 1989). Thus, for nonchillingsensitive LP produce, maintaining product temperatures at only 1 or $2 \mathrm{C}$ above the freezing point may increase high-quality shelf life by at least three- to five-fold or more as compared to storage at 10C. Thus, the paramount marketing tool for LP produce is strict avoidance of temperature abuse during processing, distribution, and merchandising to achieve the required or near maximum shelf life for each production batch of each product. Unfortunately, there is little doubt that temperature abuse of LP produce during distribution and sale is ubiquitous in the United States (Eames, 1993, personal communication).

\section{Retarding moisture loss}

Moisture loss from LP fruits and vegetables via evaporation reduces sensory quality by causing wilt, shrivel, and turgor lossinduced reduction of crispness. The use of packaging materials to retard moisture loss helps to maintain sensory quality. Most often, flexible polymeric films are used to retard the rate of moisture loss, and many films used for this purpose have perforations to minimize the potential for development of anaerobic conditions within the package atmosphere. Surface coatings of wax might also retard moisture loss (Wills et al., 1989).

\section{Altering the composition of the atmosphere around the product}

LP fruits and vegetables are living tissues that are undergoing catabolic metabolism and respiration. Steps taken to reduce respiration rates also may reduce the rate of sensory quality degradation due to oxidative changes of pigment and lipid systems, and may slow down the oxidative biochemical changes leading to tissue senescence. Packaging LP produce in permeable polymeric film, semirigid containers, or both can reduce $\mathrm{O}_{2}$ concentration and increase $\mathrm{CO}_{2}$ concentration in the package atmosphere, thereby slowing degradative quality changes and increasing product shelf life. Unfortunately, the degree to which the internal package atmosphere is altered is controlled by many factors, including the nature and thickness of the packaging polymer and its surface area relative to the weight and kind of LP produce contained. Thus, inordinately low $\mathrm{O}_{2}$ concentrations, inordinately high $\mathrm{CO}_{2}$ concentrations (which may severely degrade product quality as a consequence of the onset of anaerobic respiration), or both can be unwittingly attained if extensive research and empirical testing of the product $\times$ package $\times$ temperature interactions are not carried out.

\section{Product packaging}

Packaging is necessary to limit mechanical damage to the product during distribution. It is also used, via labeling, to identify the product, provide a brand identity, and convey important information, such as use-by dating, preparation instructions, nutrient information, and storage instructions. Packaging graphics, although often expensive, are a vital aspect of successfully marketing LP fruits and vegetables (especially those that are processed by nationwide and regional producers).

\section{Product microbiology}

LP fruits and vegetables are processed from fresh fruits and vegetables that can be contaminated with many spoilage microbes, including yeasts, molds, and bacteria. Furthermore, some of the bacteria that may be present, including Clostridium botulinum and Listeria monocytogenes, are pathogenic to consumers; other pathogens, including Staphylococcus aureus and Streptococcus spp., could contaminate produce via food handlers (O'Beirne, 1990). Thus, strict adherence to sanitation and Food and Drug Administration-mandated Good Manufacturing Practices (GMPs) is essential for successfully marketing LP fruits and vegetables. Thorough washing to remove soil and contaminants is necessary, as is the use of chlorinated water, to reduce microbial loads on LP products before packaging. Maintaining a low-temperature processing environment is also recommended. Quality controls, including Hazard Analysis Critical Control Point (HACCP) methodologies, are essential tools to assure that wholesome products with adequate high-quality shelf life are produced. Because free moisture increases the potential for microbial growth on LP produce, removal of wash and cleaning water by centrifugation or other methods is critical (Cantwell, 1992).

\section{INHERENT AND INTRINSIC CHARACTERISTICS OF LP FRUITS AND VEGETABLES THAT ASSIST THEIR MARKETABILITY}

The total market for fresh fruits and vegetables has risen faster than for any other group of farm products. This increased consumer interest in fruits and vegetables as "health foods" with zero cholesterol, low to no fat and sodium, and high levels of vitamins, minerals, and fiber has accelerated an increased effort throughout the marketing system to improve quality via increasing the use of the latest technology to grade, store, transport, and merchandise produce (How, 1990). Contributing to this increased consumer interest in the consumption of fruits and vegetables is the National Research Council dietary recommendations (National Research Council, 1989) that include the following: "Every day eat five or more servings of a combination of vegetables and fruits (especially green and yellow vegetables and citrus fruits)." The U.S. Dept. of Health and Human Services (1989) publication entitled "The Surgeon General's Report on Nutrition and Health" also encourages increased consumption of fruits and vegetables. Consumer perception seems to center on the consumption of fresh or "fresh-like" fruits and vegetables rather than canned and frozen products to meet the "fivea-day" recommendation.

\section{TECHNIQUES USED FOR MARKETING LP FRUITS AND VEGETABLES}

Factors used to enhance the marketability of specific LP fruits and vegetables include assured delivery of "just-in-time" quantities of products to multiple customers via refrigerated vehicles in short periods. Capability to deliver finished products to customers within 24 to 36 hours from receipt of an order is considered a vital merchandising asset. Other advantages of LP fruits and vegetables that are often used to promote marketing to food service customers include:

-Prepackaging allows for more efficient portion control.

- Labor costs for preparation are reduced.

-Solid waste disposal problems are reduced.

-Demands on limited refrigerated storage space are reduced.

-Inventory of raw produce is minimized.

-A wide variety of menu items, including unusual or unique salad combinations, can be available throughout the year.

-A supply of ready-to-eat items that exhibit excellent uniformity of quality and identity is available over many weeks or months.

\section{DOMESTIC SOURCES OF FRESH FRUITS AND VEGETABLES AND LOCATION OF PRECUT PROCESSING FACILITIES}

According to How (1990), sourcing is one of the most important factors concerned with marketing fresh produce in the United States. California produces $35 \%$ of domestically grown vegetables and $44 \%$ of fruits and nuts; Florida produces $13 \%$ of domestic vegetables and $31 \%$ of domestic fruit. To maintain 12-month availability of various products, e.g., table grapes and peaches, domestically grown produce is supplemented with imports of fresh commodities. LP products can be prepared, processed, and packaged at the source of production, at regional processing centers, or at local sites. Whether a specific LP product is processed at its production (growing) area or at regional or local sites remote from the growing area depends on the "perishability of the processed form relative to the intact form, and on the quality 
required for the designated use of the product" (Cantwell, 1992). As Cantwell (1992) reported, there are distinct advantages and disadvantages associated with minimally processing fruits and vegetables at local, regional, or growing area locations.

When minimal processing is conducted at growing areas, the product can be obtained (harvested) at peak quality, but the processed, packaged, finished product then requires a minimum 14 days of postprocessing shelf life. Processing at the site of production avoids the need to transport unusable portions of product, such as lettuce cores, but requires excellent postprocessing temperature management. A delivery radius of up to $\approx 4000 \mathrm{~km}$ can be serviced by processors located at the growing areas.

When minimal processing is conducted at regional processing facilities, remote from growing areas, good-quality produce is processed 3 to 7 days after harvest. However, a postprocessing, minimum shelf life of 7 days is necessary, and good temperature management is vital. Regional processing allows greater flexibility in terms of responding to customer delivery requirements and requires less use of differentially permeable polymeric packaging. A delivery radius of up to several hundred kilometers is usually serviced by regional processors.

When minimal processing is conducted at local processing facilities remote from growing areas, produce of adequate to good quality is processed 3 to 14 days after harvest and a short ( 1 to 3 days) postprocessing shelf life is necessary. Small quantities of specialty products unique to a single customer can be processed and delivered on short notice using simple package materials. Good temperature management is necessary, as is a significant inventory of fresh produce and sufficient refrigerated storage space. According to Eames (1993), processing losses of up to $50 \%$ are normal for local processors; therefore, raw produce inventories about double the size of sales volume are often required. When minimal processing is performed by local processors, a delivery radius of more than 80 to $160 \mathrm{~km}$ from the processing site is rarely exceeded. Local processing has the advantage of providing highly flexible, rapid delivery of the finished product, often within hours of receipt of a customer order. Thus, local processors must maintain highly adaptable processing capabilities as well as a readily available, versatile labor force.

\section{POTENTIAL GROWTH MARKETS FOR LP FRUITS AND VEGETABLES}

LP produce made its debut in the food service industry (Gertmenian, 1992). Now, the retail market is opening to LP produce, and where the average supermarket in 1990 had not a single package of LP produce, in 1992-93, there may be from 1 to $3 \mathrm{~m}$ of refrigerated display space with up to 12 or more products. All of the major club chains are adding produce departments, and retail is the new growth area for the fresh produce processor (Gertmenian, 1992). Club chains are huge users of value-added produce and usually offer $\approx 1.4-$ and $\approx 2.3-\mathrm{kg}$ bags of fresh-cut produce (Niedens, 1993). Produce departments in retail stores are predicted to average 30\% more space by 2010 than in 1993 (Hager, 1993). The precut business is growing-it started as an institutional (food service) business, but there is a real trend toward convenient items in the supermarket (Crothers, 1992). The fresh-cut produce industry has leapfrogged the restaurant salad bar and landed in the refrigerated cooler at the supermarket produce department (Krause, 1992).

The number of precut processors is growing, as is the variety of products. In 1990, precut produce accounted for only $\approx 1 \%$ of total fresh produce industry volume. By 2000 , precut produce could be a $\$ 4$ to $\$ 8$ billion market (Zind, 1990). There is considerable promise for a vast increase in the precut produce market via retail/supermarket sales. The major impetus for the projected increase in retail marketing of precut produce is in the area of packaged fruit salads and mixed vegetable salads that can provide convenience for home consumption of fresh fruits and vegetables. Whether this promise is achieved depends in large measure on the application of strict sanitation in processing, improved technology in packaging, and an intense commitment to strict attention to maintaining correct low temperatures throughout the cold chain, from distribution, storage, and display to handling and use by the consumer. Success will ultimately depend on providing a safe, wholesome product with "fresh-like" quality at the consumer's table.

\section{Literature Cited}

Allen, J.W. and T.R. Pierson. 1988. Fresh prepared foods: Marketing opportunities and challenges for rapid growth. Food Industry Inst., Michigan State Univ., East Lansing.

Best, D. 1991. Designing new products from a market perspective, p. 1-27. In: E. Graf and I.S. Saguy (eds.). Food product development from concept to the marketplace. Van Nostrand Reinhold, New York.

Cantwell, M. 1992. Postharvest handling systems: Minimally processed fruits and vegetables, p. 277-281. In: A.A. Kader (ed.). Postharvest technology of horticultural crops. 2nd ed. Univ. of California, Division of Agriculture and Natural Resources, Davis. Publ. 3311.

Cook, R.L. 1992. The dynamic U.S. fresh produce industry: An overview, p. 3-13. In: A.A. Kader (ed.). Postharvest technology of horticultural crops. 2nd ed. Univ. of California, Division of Agriculture and Natural Resources, Davis. Publ. 3311.

Crothers, D. 1992. Packaging technology extends reach of precuts. Produce Business Aug. 1992. p. 33.

Gertmenian, D. 1992. Maximum shelf life is critical in fresh cut marketing. Produce Business Oct. 1992. p. 76.

Hager, D. 1993. Produce: A growing retail sector. The Packer 18 Dec. 1993. p. 20.

How, R.B. 1990. Marketing fresh fruits and vegetables. Van Nostrand Reinhold, New York

Krause, S. 1992. Next big frontier is ready for fresh cut produce. The Packer 19 Sept. 1992. p. 68.

National Research Council. 1989. Diet and health: Implications for reducing chronic disease risk. National Academy Press, Washington, D.C.

Niedens, L. 1993. Fresh-cut without the frills. The Packer 18 Dec. 1993. p. 30.

O'Beirne, D. 1990. Modified atmosphere packaging of fruits and vegetables, p. 183-199. In: T.R. Gormley (ed.). Chilled foods, The state of the art. Elsevier Science Publishing Co., New York.

U.S. Dept. of Health and Human Services. 1989. Surgeon General's report on nutrition and health. U.S. Government Printing Office, Washington, D.C.

Wills, R.B.H., W.B. McGlasson, D. Graham, T.H. Lee, and E.G. Hall. 1989. Postharvest, An introduction to the physiology and handling of fruit and vegetables. 3rd ed. Van Nostrand Reinhold, New York.

Zind, T. 1990 . Age of pre-cut: $\$ 4-8 B$ market seen by 2000 . The Packer 21 Apr. 1990. p. 1A. 